\title{
Erythrolobus australicus sp. nov. (Porphyridiophyceae, Rhodophyta): a description based on several approaches
}

\author{
Eun Chan Yang ${ }^{1}$, Joe Scott ${ }^{2}$, John A. West ${ }^{3, *}$, Hwan Su Yoon ${ }^{1,4}$, Akiko Yokoyama ${ }^{5}$, Ulf Karsten ${ }^{6}$, \\ Susan Loiseaux de Goër ${ }^{7}$ and Evguenia Orlova ${ }^{2}$
}

${ }^{1}$ Bigelow Laboratory for Ocean Sciences, P.O. Box 475, 180 McKown Point Road, West Boothbay Harbor, ME 04575, USA

${ }^{2}$ Department of Biology, College of William \& Mary, Williamsburg, VA 23187, USA

${ }^{3}$ School of Botany, University of Melbourne, Parkville, Victoria 3010, Australia

${ }^{4}$ Department of Biological Science, Sungkyunkwan University, Suwon 440-746, Korea

${ }^{5}$ Structural Biosciences, Graduate School of Life and Environmental Sciences, University of Tsukuba, 1-1-1 Tennodai, Tsukuba, Ibaraki Pref. 305-8572, Japan

${ }_{6}^{6}$ Institute of Biological Sciences - Applied Ecology, University of Rostock, Albert-Einstein-Strasse 3, D-18057 Rostock, Germany

${ }^{7} 11$ Rue des Moguerou, 29680 Roscoff, France

The unicellular marine red alga Erythrolobus australicus sp. nov. (Porphyridiophyceae) was isolated into laboratory culture from mangroves in Queensland and New South Wales, Australia. The single multi-lobed red to rose-red plastid has more than one pyrenoid and lacks a peripheral thylakoid. Arrays of small electron dense globules occur along the thylakoids. The nucleus is peripheral with a central to eccentric nucleolus. Each Golgi body is associated with a mitochondrion. The spherical cells are positively phototactic with slow gliding movement. The $p s a \mathrm{~A}+p s b \mathrm{~A}$ phylogeny clearly showed that E. australicus is a distinct species, which is closely related to E. coxiae. The chemotaxonomically relevant and most abundant low molecular weight carbohydrate in E. australicus is floridoside with concentrations between 209 and $231 \mu \mathrm{mol} \mathrm{g}{ }^{-1}$ dry weight. Traces of digeneaside were also detected. These various approaches help to understand the taxonomic diversity of unicellular red algae.

Key Words: Australia; digeneaside; Erythrolobus; floridoside; molecular phylogeny; Porphyridiophyceae; ultrastructure; unicells

\section{INTRODUCTION}

The class Porphyridiophyceae of the division Rhodophyta forms a monophyletic group based on molecular data and is distinguished from other unicellular red algae by having specific ultrastructural features: Golgi bodies always associated with mitochondria and peripheral thylakoids absent in the plastid (Yang et al. 2010). Currently the class is comprised of four genera: Porphyridium with about 4 species [P. purpureum (Bory de
Saint-Vincent) K. M. Drew \& R. Ross, P. sordidum Geitler, P. aerugineum Geitler and P. marinum Kylin] (Guiry and Guiry 2011); Flintiella with one species, F sanguinaria Ott; Erythrolobus with two species, E. coxiae J. Scott et al. and E. madagascarensis E. Yang et al.; Timspurckia, with one species, T. oligopyrenoides E. Yang et al.

In Flintiella a pyrenoid is absent. In Porphyridium a single central pyrenoid is embedded within the plastid (c) This is an Open Access article distributed under the terms of the Creative Commons Attribution Non-Commercial License (http://creativecommons.org/licenses/by-nc/3.0/) which permits unrestricted non-commercial use, distribution, and reproduction in any medium, provided the original work is properly cited.
Received 3 March 2011, Accepted 20 April 2011

*Corresponding Author

E-mail: jwest@unimelb.edu.au

Tel: +61-3-8344-8080, Fax: +61-3-9349-3268 
and the nucleus has a peripheral nucleolus. In Erythrolobus one or more 'naked' pyrenoids (bordering the cytoplasm) and a nucleus with a central or eccentric nucleolus are present. In Timspurckia 2-4 naked pyrenoids per cell and a nucleus with a peripheral nucleolus are present. In Porphyridium (Gantt and Conti 1965, Gantt et al. 1968, Schornstein and Scott 1982) the pyrenoid is traversed by thylakoids that appear to be flattened sheets (cisternae) while pyrenoids in Erythrolobus species and Timspurckia are traversed by tubular thylakoids (Yang et al. 2010). Molecular evidence clearly shows these genera to be in distinct clades (Yang et al. 2010).

The application of chemical characters has long been important in algal systematics. The distribution of low molecular weight carbohydrates (LMWCs) are useful chemotaxonomic characters particularly in red algae (Karsten et al. 1999, 2003). For an organic molecule to be useful as a chemotaxonomic character, it must be specific to a certain taxon or group of organisms. The distribution patterns of the main LMWC floridoside ( $\alpha$-D-galactopyranosyl-[1-2]-glycerol) and digeneaside ( $\alpha$-D-mannopyranosyl-[1-2]-glycerate), have been applied as chemotaxonomic characters in various red algae (Karsten et al. 1999, 2003, Eggert and Karsten 2010, Yang et al. 2010).

We have chosen the name Erythrolobus australicus sp. nov. for two marine unicellular red algal culture isolates from Queensland and New South Wales, Australia. They are closely related to E. coxiae and E. madagascarensis but $E$. australicus has 2-3 pyrenoids and arrays of electron dense bodies between the thylakoids forming a clade clearly distinguished from other lineages indicating it is a different species.

\section{MATERIALS AND METHODS}

\section{Culture methods}

Methods for collection, isolation and maintenance of cultures are presented in West and Zuccarello (1999) and West (2005). To promote growth of target unicellular red algae low nutrient levels were used initially $(2 \mathrm{~mL}$ modified-Provasoli-media [MPM] enrichment per liter of sterile seawater). The seawater was adjusted to $30 \mathrm{psu}$ with Milli-Q water (Millipore Corp., Billerica, MA, USA). Careful weekly observations with a dissecting stereomicroscope detected developing unicell colonies that were removed by a $100 \mu \mathrm{L}$ micro-pipet and subcultured in 50 $\times 70 \mathrm{~mm}$ crystallizing dishes containing 30 psu seawa- ter with $10 \mathrm{~mL}$ MPM enrichment per liter. Most cultures were maintained in $18-22^{\circ} \mathrm{C}, 5-20 \mu \mathrm{mol}$ photons $\mathrm{m}^{-2} \mathrm{~s}^{-1}$ cool white fluorescent lighting with a $12: 12 \mathrm{LD}$ daily cycle. For low molecular weight carbohydrate analysis cultures were dried at $60^{\circ} \mathrm{C}$ and sent to UK.

\section{Bright field microscopy}

A small drop of cultured cells was placed on a glass slide, covered with a coverslip and sealed on the edges with VALAP (Pickett-Heaps et al. 2001). Motility of individual cells was followed for 5-10 min but no videomicroscopy was done. Images of live cells were taken on a Zeiss GFL microscope (Carl Zeiss, Thornwood, NY, USA) with a Canon G3 digital camera (Canon, Tokyo, Japan). Images were processed with Adobe Photoshop CS4 (Adobe Systems Incorporated, San Jose, CA, USA) for publication figures.

\section{Confocal microscopy}

Isolates were cultured with $10 \mathrm{~mL}$ ESM medium (Okaichi et al. 1982) in glass culture tubes for two weeks before fixation. Cultured cells were then transferred to $1.5 \mathrm{~mL}$ microtubes with $0.5 \mathrm{~mL}$ of culture medium, fixed with equal volume of $3 \%$ paraformaldehyde in PHEM buffer [60 mM PIPES, 25 mM HEPES, 10 mM EGTA, 2 mM $\mathrm{MgCl}_{2}\left(6 \mathrm{H}_{2} \mathrm{O}\right)$, $\left.\mathrm{pH} 7.4\right]$ for $15 \mathrm{~min}$. Ten $\mu \mathrm{L}$ of the fixative solution were placed on a glass slide coated with $0.1 \mathrm{w} / \mathrm{v} \%$ poly-L-lysine and incubated for $10 \mathrm{~min}$ at room temperature. Then equal volumes of SlowFade ${ }^{\circledR}$ Antifade (Invitrogen, Carlsbad, CA, USA) and 1,000 $\times$ diluted SYBR ${ }^{\circledR}$ Green I (Invitrogen) were added and incubated for $15 \mathrm{~min}$. Confocal images were taken with an inverted microscope Axiovert 100M with LSM 510 laser scanning equipment (Carl Zeiss AG, Jena, Germany). Plastid autofluorescence and SYBR Green I fluorescence were detected with a 585 $\mathrm{nm}$ long pass filter, 505 to $530 \mathrm{~nm}$ band pass filter, respectively, in the excitation line of a $488 \mathrm{~nm}$ argon laser and $543 \mathrm{~nm} \mathrm{He} / \mathrm{Ne}$ laser using single-track mode as described in Hirakawa et al. (2010).

\section{Transmission electron microscopy}

Cells from culture were filtered onto poly-L-lysine coated $0.45 \mu \mathrm{m}$ Millipore ${ }^{\mathrm{TM}}$ filters and fixed for $2 \mathrm{~h}$ at ambient temperature in $2 \%$ glutaraldehyde in a $0.1 \mathrm{M}$ phosphate buffer solution ( $\mathrm{pH}$ 6.8) with $0.15 \mathrm{M}$ sucrose. Following buffer rinses samples were post-fixed $1 \mathrm{~h}$ in the same buffer with $1 \% \mathrm{OsO}_{4}$ at $4^{\circ} \mathrm{C}$, rinsed thoroughly in 
$\mathrm{H}_{2} \mathrm{O}$, left in $50 \%$ acetone for $30 \mathrm{~min}$ and stored in a $70 \%$ acetone- $2 \%$ uranyl acetate solution at ambient temperature for $20 \mathrm{~h}$. Samples were then further dehydrated in a graded acetone series, infiltrated gradually and embedded in Spurr's resin and polymerized at $70^{\circ} \mathrm{C}$ for 2-3 days. Thin sections were cut with an RMC MT6000-XL ultramicrotome (RMC Inc., Tucson, AZ, USA). Sections were stained 1 min with lead acetate. A Zeiss EM 109 electron microscope was used for observation and photography.

\section{Molecular analyses}

Genomic DNA was extracted from each culture strain using a DNeasy Plant Mini Kit (Qiagen, Hilden, Germany), according to the manufacturers' instructions. PCR and sequencing were performed as described in Yang et al. (2010). Specific primer sets for two plastid genes were used: psaA130F-psaA1110R and psaA971F-psaA1760R for $p s a \mathrm{~A}$ and psbAF-psbAR2 for $p s b \mathrm{~A}$. Amplified DNA was purified with the QIAquick PCR purification kit (Qiagen) and sent to a commercial sequencing company. The electropherogram output for each specimen was edited using the program Chromas version 1.45 (http://www. technelysium.com.au/chromas.html). Newly determined $p s a \mathrm{~A}$ and $p s b \mathrm{~A}$ sequences (JF440648-JF440651) were compared and aligned with published data by using program Se-Al version 2.0a11 (http://tree.bio.ed.ac.uk/software/seal/). The translated amino acid sequences were used for the DNA alignment. The introns of $p s a$ A (Yoon et al. 2006, 2010) were excluded in subsequent analyses.

Appropriate evolution models for DNA and protein data were selected by the program ModelGenerator v.0.85 (Keane et al. 2006). Based on Akaike Information Criterion (AIC) and Bayesian Information Criterion (BIC), general time reversible (GTR) substitution model for DNA and LG (Le and Gascuel 2008) for protein were selected as the best fit evolution models, respectively. Maximum likelihood (ML) analyses were performed using RAxML version 7.2.6 (Stamatakis 2006). Tree likelihoods were estimated using 100 independent replications using an unfixed GTR with rate heterogeneity among sites (gamma distribution, $\Gamma$ ) parameter. Automatically optimized Sub-tree Pruning and Reconnection (SPR) rearrangement with rapid hill climbing algorhythm was used for the best tree search. Maximum parsimony (MP) analyses were conducted using the PAUP* version 4.0b10 (Swofford 2002). The heuristic search was carried out with 1,000 replicates, random sequences addition and Tree Bisection Reconnection (TBR) branch swapping. Bootstrap analyses were carried out with 1,000 replicates to test of monophyly under the same ML (MLBt) and MP (MPBt) condition.

Bayesian analysis for DNA data was conducted with MrBayes version 3.2 (Ronquist and Huelsenbeck 2003) using GTR $+\Gamma$ parameter, which was same evolution model in ML analyses. The GTR rates and $\Gamma$ values were not fixed. Two independent runs of 2 million generations were performed with four chains and trees were sampled every 100 generations. The burn-in point was identified by the average of standard deviation from split frequencies $(<0.01)$ between two independent runs. Trees sampled after the burn-in point were used to infer the Bayesian posterior probability (BPP).

\section{Low molecular weight carbohydrates (LMWC) analyses}

Both heterosides (floridoside and digeneaside) were separated and quantified by high-performance liquid chromatography (HPLC). For the chromatographic analyses, 10-15 mg dry weight (DW) of red algal samples were extracted in $1 \mathrm{~mL}$ of $70 \%(\mathrm{v} / \mathrm{v})$ ethanol and heated for 3 $\mathrm{h}$ in a waterbath at $70^{\circ} \mathrm{C}$. After centrifugation for $5 \mathrm{~min}$ at $6,200 \times \mathrm{g}, 700 \mathrm{~mL}$ of the supernatant were evaporated to dryness under vacuum (Speed Vac Concentrator SVC 100H; Savant, Farmingdale, NY, USA). Dried extracts were redissolved in $700 \mathrm{~mL}$ of distilled water, sonicated for 1 $\min$ and vortexed for $30 \mathrm{~s}$. After centrifugation at 16,000 $\times \mathrm{g}$, the supernatants were analysed with an isocratic Agilent HPLC system equipped with a differential refractometer. The LMWCs were separated (floridoside and digeneaside) using a resin-based Phenomenex (Rezex ROA-Organic Acid, $300 \times 7.8 \mathrm{~mm}$ O.D.) column protected with a Phenomenex Carbo- $\mathrm{H}+$ guard cartridge $(4 \times 3 \mathrm{~mm}$ I.D.) and quantified with an isocratic Agilent HPLC system equipped with a differential refractometer (Karsten et al. 2005). On this column both heterosides were eluted with $5 \mathrm{mM} \mathrm{H}_{2} \mathrm{SO}_{4}$ at a flow rate of $0.4 \mathrm{~mL} \mathrm{~min}^{-1}$ at $75^{\circ} \mathrm{C}$. Peaks on both columns were identified by comparison of the respective retention times with those of standard compounds and quantified by peak areas. The concentrations were expressed in $\mu \mathrm{mol} \mathrm{g}^{-1} \mathrm{DW}$.

\section{RESULTS}

\section{Diagnosis}

Erythrolobus australicus sp. nov. E. C. Yang, J. L. Scott et J. A. West. Cellulae sphaericae 10-20 $\mu$ m diametro, ma- 
trice extracellulari $<1 \mu \mathrm{m}$ crassa, roseo-rubrae vel rubrae, phototacticae. Plastidus singulis lobis multis extensis a pyrenoidibus multis per totam cellulam distributis; pyrenoidibus thylacoides tubulares numerosas continentibus, cytoplasmati expositis, plerumque granulis amyli circumcinctis; thylacoidibus peripheralibus nullis. Consocies globulorum parvorum $(30-60 \mathrm{~nm})$ uniformium electronibus opacorum inter thylacoides saepe visae. Omne corpus Golgi uno mitochondrio semper consociatum et prope peripheriam cellulae positum. Nucleus peripheralis nucleolo singulo centrali vel excentrico. Carbonii hydrata parvi ponderis floridosidum et digeneasidum.

Cells spherical, $10-20 \mu \mathrm{m}$ in diameter, extracellular matrix $(<1 \mu \mathrm{m}$ thick), rose-red to red, phototactic. Single plastid with numerous lobes extending from multiple pyrenoids located throughout the cell. Pyrenoids containing numerous tubular thylakoids border the cytoplasm and usually surrounded by starch granules. Peripheral thylakoids are absent. Arrays of small (30-60 nanometers) uniform electron dense globules often occur between thylakoids. Each Golgi body always associated with a mitochondrion and located near the cell periphery. The nucleus peripheral with a single central to eccentric nucleolus. LMWCs are floridoside and digeneaside. Holotype: Cryopreserved culture- CCMP 3123 (JAW3904). Paratype: Cryopreserved culture - CCMP 3124 (JAW4188). Bigelow Laboratory for Ocean Sciences, P.O. Box 475, 180 McKown Point Road, West Boothbay Harbor, ME 04575, USA.

Iconotype: Figs 1-3 of this paper.

Live culture specimens: holotype, CCAP 1393/7 (JAW 3904); paratype, CCAP 1380/8 (JAW4188). Culture Collection of Algae and Protozoa, Scottish Association for Marine Science, Scottish Marine Institute, Dunstaffnage Marine Laboratory, Dunbeg, Oban, Argyll, PA37 1QA, UK. Holotype locality: Culture 3904 was isolated from a cultured specimen of Caloglossa vieillardii (Kützing) W. Setchell collected by G. C. Zuccarello and J. A. West on 25 July 1998, at Tewantin, Queensland, Australia $\left(26^{\circ} 23^{\prime}\right.$ $\left.\mathrm{S} 153^{\circ} 02^{\prime} \mathrm{E}\right)$.

Paratype locality: Culture 4188 was isolated from a cultured specimen of Bostrychia moritziana (Sonder ex Kützing) J. Agardh collected by G. C. Zuccarello on 1 October 2001 at Woolooware Bay, New South Wales, Australia ( $\left.34^{\circ} 01^{\prime} \mathrm{S} 151^{\circ} 09^{\prime} \mathrm{E}\right)$.

\section{Bright field microscopy}

The cell diameter of both isolates varied from 10-20 $\mu \mathrm{m}$ in diameter. The cellular details were difficult to discern with conventional brightfield microscopy. Even with a careful through-focus it was hard to see more than one pyrenoid in many cells but when the cell preparation was fully flattened by the weight of the coverslip, pyrenoids (Fig. 1A \& E) and the nucleus (Fig. 1E) were more visible. The dark refractive outline of starch grains around the pyrenoid aided in their identity. The narrow fissures between plastid lobes were especially visible when focused at the outermost level (Fig. 1F). During observations on cell motility the cells remained spherical and rotated slowly while gliding without substrate contact. Polysaccharide tails visible on some cells (Fig. 1B \& G) did not appear to be involved in movement.

\section{Confocal microscopy}

Late stages of cell division were observed in cells of 3904 (Fig. 1C). The nucleus was 3.2-3.5 $\mu \mathrm{m}$ in diameter and positioned near the perimeter between plastid lobes. The plastid divided after the nucleus. Plastid genophores were spherical to elongate up to $0.37-0.55 \mu \mathrm{m}$ long. As many as 15 genophores were visible in a single optical section but it was not possible to determine if they were connected. In isolate 41883 pyrenoids (Fig. 1D) were visible as dark areas (2.4-2.8 $\mu \mathrm{m}$ in diameter) when a series of focal levels were photographed.

\section{Transmission electron microscopy}

Since both isolates of Erythrolobus australicus sp. nov. were collected approximately $1,000 \mathrm{~km}$ from each other, it was of interest to determine if cellular details of each isolate were also indistinguishable. Therefore, ultrastructural features of each isolate are presented separately.

Isolate 3904 - Queensland. Most transmission electron microscopy (TEM) observations revealed cells showing either a single pyrenoid and / or nucleus. However, examination of numerous thin sections and hundreds of cells provided views of cells with a medially sectioned nucleus and one or more pyrenoids (Fig. 2A). Occasionally three pyrenoids were seen in a single non-dividing cell (Fig. 2B). The extracellular sheath is faintly visible and approximately $0.5 \mu \mathrm{m}$ thick. A peripheral endoplasmic reticulum (ER) system was just beneath the cell membrane (Fig. 2B) but short tubules that interconnected this system with the cell membrane, as seen in many red algal unicells (Scott et al. 2006), were not detected. The 2.5-3.0 $\mu \mathrm{m}$ nuclei (Fig. 2A) contained a single central to eccentric nucleolus and were usually near the cell periphery but 

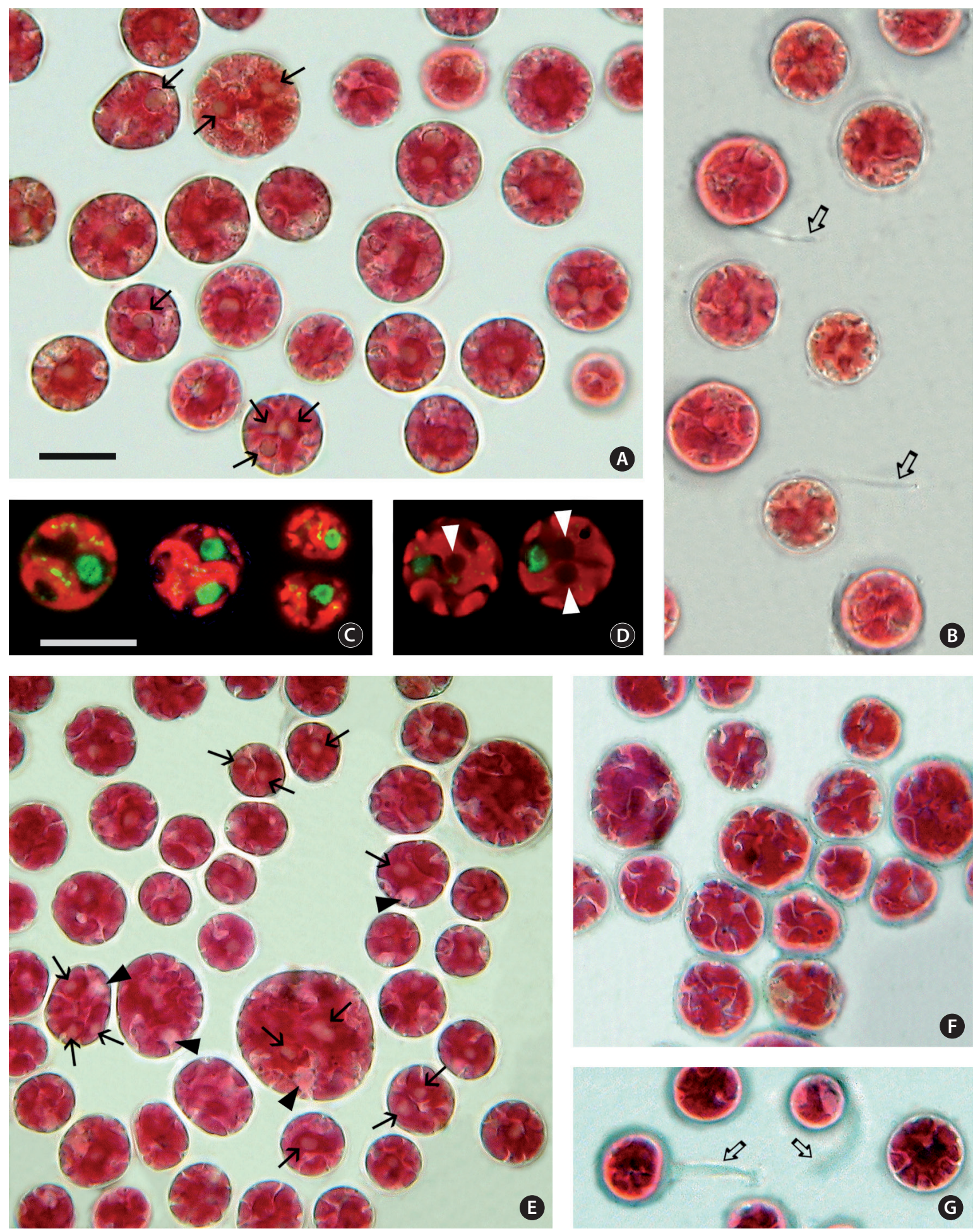

Fig. 1. Erythrolobus australicus sp. nov. Bright field microscopy (A, B \& E-G). Confocal microscopy (C \& D). Fluorescent SYBR Green showing the nucleus (green), plastid genophores (yellow) and plastid autofluoresence (red). Isolate 3904 in A-C, and isolate 4188 in D-G. (A) Most plastids with only one pyrenoid visible, some show two or three (black arrows). Bright field images do not show the pyrenoids as clearly as confocal images. (B) Some cells with a polysaccharide tail extending from the extracellular matrix (hollow arrows). (C) These views show the peripheral nucleus (green) and plastid genophores (yellow) in 3 stages of cell division. (D) Three pyrenoids (white arrowheads) are visible at different focal levels in same cell. Nucleus is peripheral on the left. (E) Bright field microscopy of various cells shows 1-3 pyrenoids (black arrows) per cell and the single nucleus (black arrowheads). (F) The narrow fissures of the multilobed plastids are distinct in cells focused at the outer surface of the cells. (G) Polysaccharide tails (hollow arrows) similar to those of 3904 in Fig. 1B are visible on some cells. Scale bars represent: A-G, $12 \mu \mathrm{m}$. 

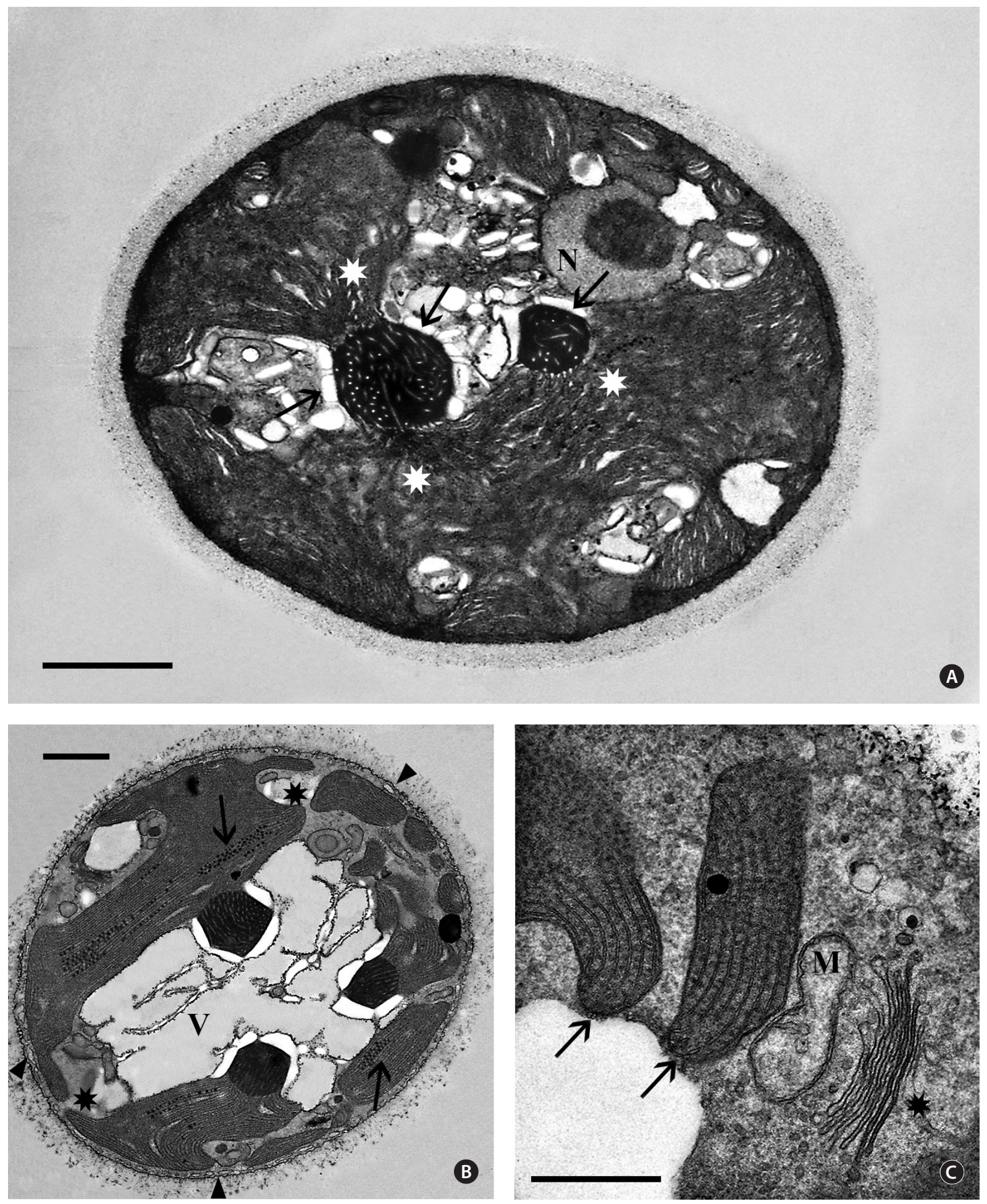

Fig. 2. Erythrolobus australicus sp. nov. (3904) ultrastructure. (A) Low magnification electron micrograph of a medially sectioned cell. Two electron dense pyrenoids containing tubular thylakoids are bounded by starch grains (arrows). The nucleus (N) contains an eccentric nucleolus. Thylakoids within plastid lobes (white asterisks) are not clearly resolved. The cell is enveloped by a thin extracellular matrix. (B) Low magnification electron micrograph of a medially sectioned cell. Three pyrenoids can be seen extending from plastid lobes into a centralized vacuole region (V). A peripheral endoplasmic reticulum system is beneath the cell membrane (arrowheads). Several random arrays of electron dense globules are present between the thylakoids (arrows) and a peripheral thylakoid is absent (asterisks). (C) High magnification electron micrograph of a Golgi body (asterisk) associated with a mitochondrion (M). A peripheral thylakoid is absent as seen in termini of plastid lobes (arrows). Scale bars represent: $\mathrm{A}, 1.8 \mu \mathrm{m} ; \mathrm{B}, 1.5 \mu \mathrm{m} ; \mathrm{C}, 0.5 \mu \mathrm{m}$. 
interior to other cellular components, mainly the plastid. Electron dense heterochromatin was never seen.

The plastid occupied the majority of the cell interior and was quite variable in shape (Fig. 2A \& B). It was obvious that plastid morphology was strongly influenced by pyrenoid numbers since plastid lobes extended from naked pyrenoids that projected into the cytoplasm. We could not determine if all cells contained multiple pyrenoids since serial thin-sectioning was not attempted. Pyrenoids appeared variable in size in thin sections, the largest being about the same size as nuclei. Many pyrenoids showed two or more connections to the plastid lobes (Fig. 2A \& B). The pyrenoids were electron dense with numerous tubular electron transparent thylakoids extending from the plastid lobes (Fig. 2A \& B). Cytoplasmic starch grains commonly were associated with the pyrenoids but were also found in other cell regions. Linear arrays of electron dense globules, $40-60 \mathrm{~nm}$ in diameter and of unknown function, were frequently seen in random locations between the thylakoids in plastids (Fig. 2B). Peripheral thylakoids were absent (Fig. 2B \& C).

Golgi bodies were found usually at the cell periphery, always in close association with a mitochondrion (Fig. 2C). Unlike most red algal unicells (Broadwater and Scott 1994), a lobed vacuolar region occurs in most cells (Fig. 2B).

Isolate 4188 - New South Wales. Cell ultrastructure of this isolate (Fig. 3) was virtually identical to that of isolate 3904. The peripheral ER system was seen in some cells but was not well preserved. Although many sectioned cells were observed, none was seen with more than two pyrenoids. The naked pyrenoids were electron dense and filled with numerous thylakoids. Some pyrenoids (Fig. 3A \& B) were associated with fewer starch grains than others (Fig. 3C). Peripheral thylakoids were not seen but hemidiscoidal phycobilisomes were more obvious (Fig. 3D) than in 3904. The nucleus was near the periphery with a single central to eccentric nucleolus (Fig. 3A, B \& C) and no visible heterochromatin. Linear arrays of electron dense globules were present between thylakoids and a vacuolar region was conspicuous. Golgi bodies associated with a mitochondrion were near the cell periphery.

\section{Molecular analyses}

Newly determined sequences were aligned with 27 sequences from Genbank, which included seven red algal classes. The $p s a \mathrm{~A}$ gene was aligned to 1,365 base pairs including 719 variable positions (52.7\%). The $p s b$ A gene was aligned to $873 \mathrm{bp}$ including 374 variable positions $(42.8 \%)$. Within the Porphyridiophyceae, sequence di- vergence of $p s a$ A ranged from $11.2 \%$ (153 nucleotide [nt]) between E. australicus and E. coxiae; to $22.3 \%$ (305 nt) between T. oligopyrenoides and P. aerugineum. The $p s b \mathrm{~A}$ gene varied by 3.8\% (33 nt) between E. australicus and $E$. coxiae; to $9.7 \%$ (85 nt) between T. oligopyrenoides and $P$. aerugineum.

ML phylogeny using concatenate $p s a \mathrm{~A}+p s b \mathrm{~A}$ data supports the monophyly of the Porphyridiophyceae $(96 \%$ MLBt, $75 \%$ MPBt and 1.0 BPP for DNA; $64 \%$ MLBt for protein data). The monophyly of the genus Erythrolobus was strongly supported (100\% MLBt, 99\% MPBt and 1.0 BPP for DNA; $100 \%$ MLBt for protein). Within the Erythrolobus clade, E. australicus was clearly separated from other Erythrolobus species but showed a sister-group relationship with the type species, E. coxiae with strong statistical supports (100\% MLBt, 99\% MPBt and 1.0 BPP for DNA; 73 MLBt for protein) (Fig. 4).

\section{LMWC analyses}

The LMWC data clearly indicate that members of the Porphyridiophyceae typically contain floridoside as their main LMWC along with digeneaside as a minor, sometimes even as a trace, component except in both E. coxiae isolates where the amount of digeneaside was relatively high (Table 1). Both E. australicus strains $(3904,4188)$ exhibited floridoside levels between 209 and $231 \mu \mathrm{mol} \mathrm{g}^{-1}$ DW and very low concentrations of digeneaside (1-1.5 $\mu \mathrm{mol} \mathrm{g}{ }^{-1} \mathrm{DW}$ ). Since the HPLC methodology for digeneaside detection and quantification exists only since 2005 (Karsten et al. 2005), earlier samples could not be analysed for this heteroside.

\section{DISCUSSION}

\section{Bright field microscopy}

Although video microscopy of cell motility was not done for either 3904 or 4188 the spherical cells showed slow gliding motility. Some cells showed long polysaccharide tails. These movements were similar to those seen in the other porphyridiophycean algae, Erythrolobus sp. (3797) from Fiji, E. madgascaarensis (4329) from Madagascar, T. oligopyrenoides (3827), from Victoria, and Porphyridium purpureum (3630), an endosymbiont of peneroplid foraminifera, that were videoed and described in (Pickett-Heaps et al. 2001, Yang et al. 2010). No amoeboid motility or pseudopodia were evident in any of these. 

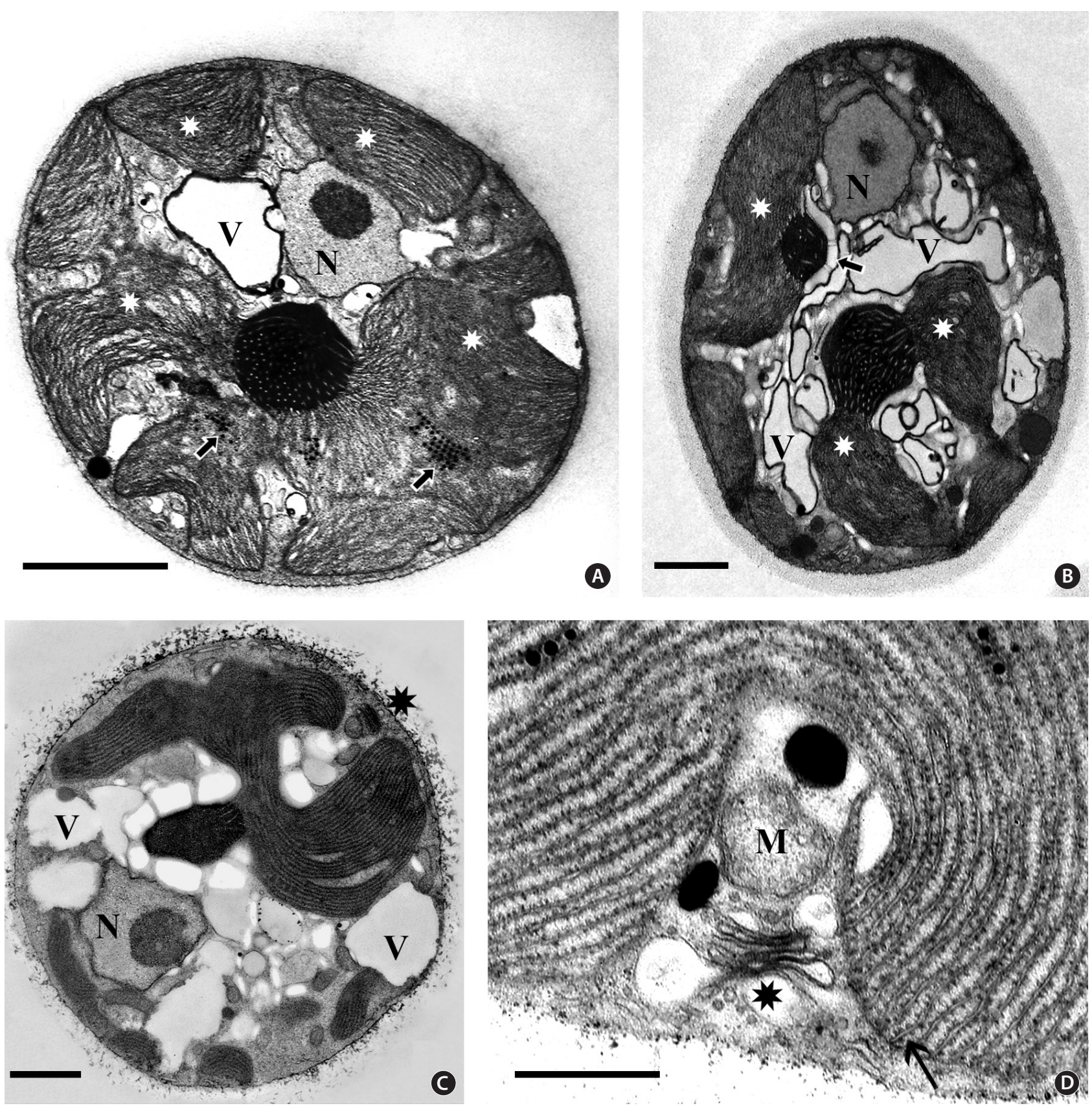

Fig. 3. Erythrolobus australicus sp. nov. (4188) ultrastructure. (A) Low magnification electron micrograph of a medially sectioned cell revealing a predominant plastid. Random arrays of electron dense globules (arrows) are present within the plastid lobes (white asterisks). A portion of the vacuolar region $(\mathrm{V})$ is next to the nucleus $(\mathrm{N})$, which contains a slightly eccentric nucleolus. The central, electron dense pyrenoid is not closely associated with starch grains. (B) Low magnification electron micrograph of a medially sectioned cell. Two pyrenoids are visible, one interconnecting plastid lobes (white asterisks) and the other appearing as a plastid lobe protrusion bordered by starch grains (arrow); Vacuolar regions (V). (C) Low magnification electron micrograph of a cell sectioned through a region revealing only a small portion of the plastid and a single pyrenoid. Nucleus (N) with eccentric nucleolus; Vacuolar regions (V); Golgi mitochondrion association (asterisk). (D) High magnification electron micrograph of a Golgi body (asterisk) associated with a mitochondrion (M). Thylakoids terminate against plastid envelope (arrow) due to absence of a peripheral thylakoid. Scale bars represent: $A, 2.3 \mu \mathrm{m} ; \mathrm{B}, 1.25 \mu \mathrm{m} ; \mathrm{C}, 1.4 \mu \mathrm{m} ; \mathrm{D}, 0.6 \mu \mathrm{m}$. 

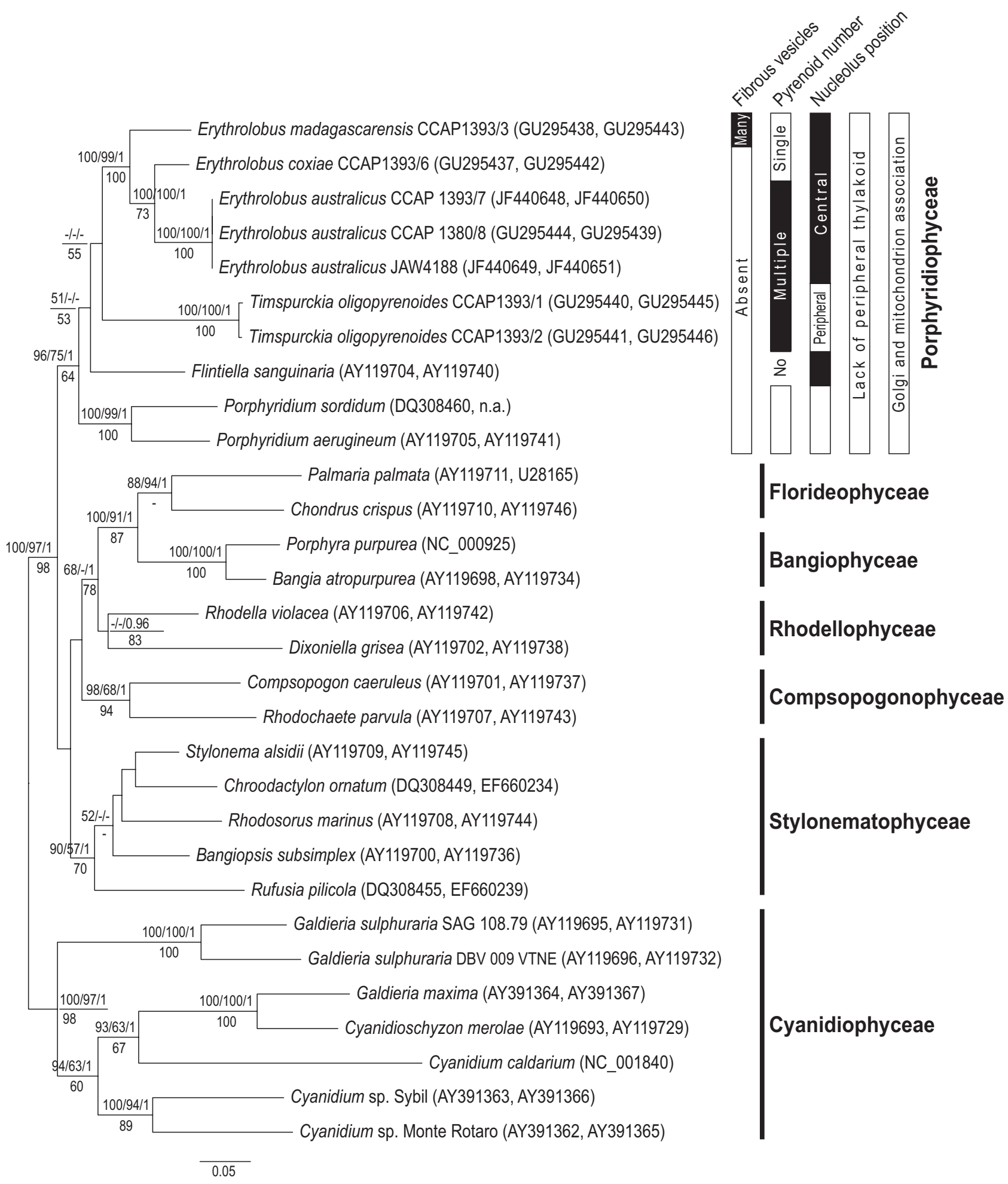

Fig. 4. The most likelihood phylogeny of Erythrolobus australicus based on psaA + psbA data $(-\operatorname{InL}=25252.028)$. Support values shown on the branch are maximum likelihood (MLBt), maximum parsimony (MPBt), and Bayesian posterior probability (BPP) from DNA data and under the branch is MLBt from protein data. Two GenBank accession numbers in parenthesis indicate $p s a \mathrm{~A}$ and $p s b \mathrm{~A}$, respectively. One accession number indicates plastid genome data. Five major ultrastructural characters of the Porphyridiophyceae were summarized. 


\section{Confocal microscopy}

Plastid genophores of E. coxiae as seen in confocal fluorescence microscopy and in TEM were spherical to subspherical and measured about $0.25 \mu \mathrm{m}$ diameter (Scott et al. 2006). By contrast those of E. australicus appear to be more variable in size and shape, spherical to elongate, localized mostly in the central plastid, not in the peripheral lobes, and perhaps up to 15 per plastid. The confocal images indicate these are individual not continuous genophores. Coleman (1985) summarizes comparative information about red algal genophores.

\section{Transmission electron microscopy}

TEM has significantly enhanced our knowledge about red algal unicells. Several new genera and species have been described since the middle of the 20th century and have been shown to differ, often subtly but sometimes dramatically, in their subcellular architecture. These differences, of course, have been a part of the basis for describing new taxa. More recently, molecular techniques have greatly contributed to unicellular red algal systematics (e.g., Yoon et al. 2006, Yang et al. 2010). Biochemistry of LMWCs also is important (Karsten et al. 1999, 2003, Scott et al. 2008, Yokoyama et al. 2009, Yang et al. 2010). These three approaches have worked in concert to establish a useful and rational explanation of unicellular red algal systematics.

Currently red algae are placed in two subphyla of the phylum Rhodophyta, the Cyanidiophytina and Rhodophytina. The three rather unusual genera, Cyanidium, Cyanidioschyzon and Galdieria, constituting the former subphylum (Yoon et al. 2010) will not be considered in our discussion. The Rhodophytina consists of six classes, two are represented only by unicells (Rhodellophyceae and Porphyridiophyceae) whereas one other class, the Stylonematophyceae, is comprised of unicells and small filamentous and pseudofilamentous multicellular algae. Numerous attempts to prepare the two unicellular genera (Rhodosorus and Rhodospora) in the Stylonematophyceae for ultrastructural studies have been mostly or completely inadequate to describe their subcellular organization (Scott personal observations).

Table 1. Low molecular weight carbohydrates (LMWCS) of Porphyridiophyceae in culture

\begin{tabular}{|c|c|c|c|c|}
\hline \multirow[b]{2}{*}{ Taxonomic assignment } & \multirow[b]{2}{*}{ Culture No. } & \multirow[b]{2}{*}{ Date } & \multicolumn{2}{|c|}{ LMWCs ( $\mu \mathrm{mol} \mathrm{g}{ }^{-1}$ dry weight) } \\
\hline & & & Floridoside & Digeneaside \\
\hline \multirow[t]{2}{*}{ Erythrolobus australicus sp. nov. } & 4188 & Dec 2009 & $209.1 \pm 10.6$ & $<1.0$ \\
\hline & 3904 & Dec 2009 & $231.0 \pm 11.9$ & $1.5 \pm 0.1$ \\
\hline \multirow[t]{2}{*}{ Erythrolobus coxiae } & 4299 & Jun 2003 & $372.1 \pm 41.2$ & $154.3 \pm 11.1$ \\
\hline & 4300 & Jun 2003 & $329.3 \pm 19.7$ & $160.8 \pm 17.2$ \\
\hline Erythrolobus madagascarensis & 4329 & Dec 2009 & $138.6 \pm 11.9$ & $19.3 \pm 2.3$ \\
\hline \multirow[t]{5}{*}{ Erythrolobus sp. } & 3797 & 2003 & $280.9 \pm 10.1$ & n.a. \\
\hline & & Dec 2009 & $169.5 \pm 0.1$ & $18.4 \pm 3.0$ \\
\hline & 4696 & Dec 2009 & $<1$ & $16.0 \pm 1.3$ \\
\hline & 4721 & Dec 2009 & $224.7 \pm 22.9$ & $30.9 \pm 4.9$ \\
\hline & 4777 & Sep 2010 & $59.9 \pm 25.3$ & $<1.0$ \\
\hline \multirow[t]{2}{*}{ Porphyridium marinum } & 2223 & 1999 & $191.0 \pm 17.0$ & n.a. \\
\hline & & Mar 2010 & $112.2 \pm 15.0$ & $5.3 \pm 0.8$ \\
\hline \multirow[t]{3}{*}{ Porphyridium purpureum } & 3630 & 1999 & $65.0 \pm 12.0$ & n.a. \\
\hline & 4126 & Mar 2010 & $127.1 \pm 20.3$ & $4.4 \pm 0.6$ \\
\hline & 4719 & Dec 2010 & $142.3 \pm 32.5$ & $18.2 \pm 4.7$ \\
\hline Porphyridium sordidum & 4778 & Sep 2010 & $38.8 \pm 5.7$ & n.t. \\
\hline \multirow[t]{3}{*}{ Timspurckia oligopyrenoides } & 3827 & 2003 & $111.8 \pm 5.2$ & n.a. \\
\hline & & 2010 & $178.8-346.7$ & 32.3-38.5 \\
\hline & 4318 & Dec 2009 & $304.2 \pm 12.2$ & $3.2 \pm 0.2$ \\
\hline
\end{tabular}

Shown are the mean values of 3-4 replicate samples ( \pm standard deviation). n.a., not analysed; n.t., no trace. 
Several ultrastructural features have proven to be of greater value than others in distinguishing the Rhodellophyceae and Porphyridiophyceae. A very simple, straight forward character is that Golgi bodies are always closely associated with a mitochondrion in the Porphyridiophyceae while they are not in the Rhodellophyceae. In the Rhodellophyceae Golgi bodies are associated either with ER or with the functionally equivalent outer membrane of the nuclear envelope (Scott et al. 2008, Yokoyama et al. 2009). Also, peripheral thylakoids are absent in plastids of all members of the Porphyridiophyceae while they are present in Dixoniella and Glaucosphaera but absent in Corynoplastis, Neorhodella, and Rhodella of the Rhodellophyceae (Scott et al. 2008). Therefore, the Porphyridiophyceae appears to be a class with the most uniform ultrastructure (Table 2). Only one other assemblage of red algae, the gametophyte (macro) stages of bangiophycean genera (Pueschel 1990), consistently shares the combination of 1) Golgi bodies associated with mitochondria and 2) the absence of a peripheral thylakoid. However, it is unlikely that these cellular features found in these two groups are phylogenetically significant since all recent accounts of red algal molecular phylogeny (Saunders and Hommersand 2004, Yoon et al. 2006, 2010) indicate a rather distant interrelationship.

Two genera of the four relegated to this class, Porphyridium and Flintiella, stand apart from the three species of Erythrolobus and Timspurckia by virtue of pyrenoid characters. Porphyridium has a pyrenoid embedded in a stellate plastid and is not in contact with the cytoplasm; Flintiella lacks a pyrenoid (Yang et al. 2010). However, the three Erythrolobus species and Timspurckia all have naked pyrenoids usually in contact with closely appressed starch grains located in the cytoplasm. Erythrolobus coxiae and E. madagascarensis differ from each other in that the nucleus is peripheral and the pyrenoid is central in $E$. coxiae while both the nucleus and pyrenoid are eccentric in E. madagascarensis. Additionally, E. madagascarensis uniquely contains numerous, conspicuous fibrous vesicles at all times (Yang et al. 2010). The similarities and differences in the previously described Porphyridiophycean species are discussed in Table 2 and Yang et al. (2010).

While evolutionarily distant from each other based on molecular analysis, at first appearance E. australicus closely resembles T. oligopyrenoides. Both species routinely possess multiple pyrenoids and their overall plastid morphology is more complex and less uniform than in E. coxiae and E. madagascarensis. However, there is a distinct and persistent dissimilarity between E. australicus and T. oligopyrenoides. The nucleolus in E. austra- licus, similar to other Erythrolobus species, is central or eccentric in the nucleus. The nucleolus in T. oligopyrenoides is always located at the periphery of the nucleus, as it is in Porphyridium (Yang et al. 2010). The function of this unusual feature is not understood but it is remarkable in that once again the molecular relationships parallel ultrastructural differences in the Porphyridiophyceae. So far as is known, each species can be recognized by its own unique ultrastructure, except possibly for Porphyridium where only two of the four reported species, $P$. purpureum (Gantt and Conti 1965) and P. aerugineum (Gantt et al. 1968), have been carefully described with TEM. A dichotomous key of the Porphyridiophyceae taxa based on ultrastructural characters is in Appendix A.

\section{Molecular phylogeny}

The topology of $p s a \mathrm{~A}+p s b \mathrm{~A}$ phylogeny was congruent with the seven-class system based on multigene data reported in previous studies (Yoon et al. 2006, Yang et al. 2010). The monophyly of the Porphyridiophyceae was strongly supported, although inter-class relationships were not fully resolved. Within the Porphyridiophyceae interrelationships among the four genera were not well resolved. Additional sequence data are needed to resolve the generic relationships within the Porphyridiophyceae.

The monophyly of the genus Erythrolobus and species level relationships within the genus were strongly supported. Erythrolobus madagascarensis was positioned sister to E. coxiae and E. australicus. The new isolates (JAW $3904=$ CCAP 1380/7 = CCMP 3123, JAW $4188=$ CCAP 1380/8 = CCMP 3124) were clearly separated from E. coxiae and E. madagascarensis. This strongly suggests that the two new isolates should be recognized as a novel species.

\section{Low molecular weight carbohydrates}

In all the Porphyridiophyceae isolates tested so far (Table 1) floridoside is the primary LMWC varying from 38 to $330 \mu \mathrm{mol} \mathrm{g}^{-1} \mathrm{DW}$ and digeneaside ranging from $<1.0$ to $154 \mu \mathrm{mol} \mathrm{g}^{-1} \mathrm{DW}$ with the exception of Erythrolobus sp. (4696) in which the digeneaside level is much greater (16 $\left.\mu \mathrm{mol} \mathrm{g}{ }^{-1} \mathrm{DW}\right)$ than floridoside $\left(1 \mu \mathrm{mol} \mathrm{g}{ }^{-1} \mathrm{DW}\right)$. Further investigation is required to understand the carbohydrate physiology of this isolate.

Floridoside is the most common LMWC and photoassimilatory product in almost all red algal orders. In contrast, members of the Ceramiales (Florideophyceae) generally synthesize and accumulate digeneaside in- 


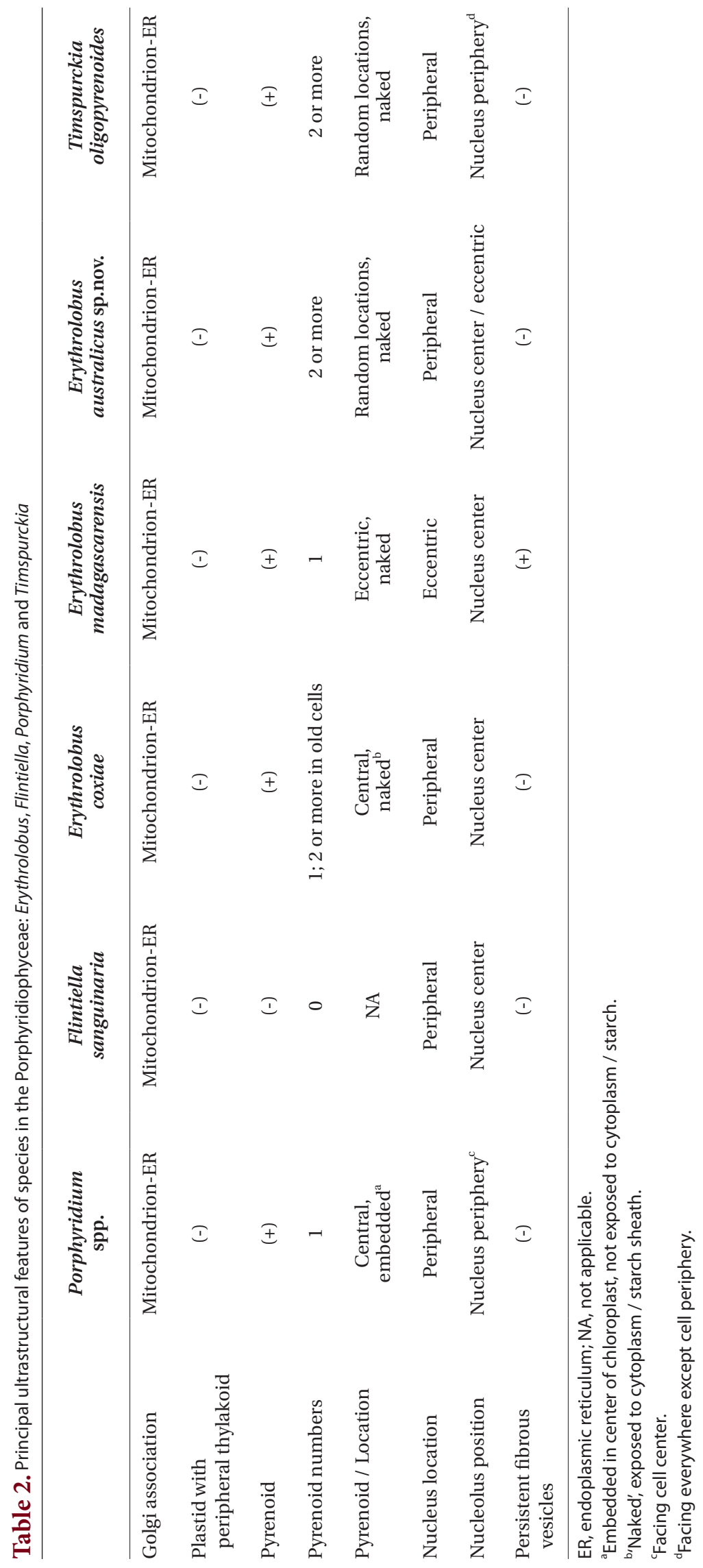


stead of floridoside, and hence the latter heteroside was proposed as chemotaxonomic marker for the Ceramiales (Kremer 1978, Eggert and Karsten 2010). However, it has been demonstrated that the ceramialean genera Laurencia and Osmundea produce and accumulate floridoside instead of digeneaside (Barrow et al. 1995). In addition, members of other red algal orders such as the Gigartinales (Florideophyceae) contain floridoside along with digeneaside (Karsten et al. 2007). The same is true for the investigated porphyridiophyceaen strains of the present study. Consequently, the use of digeneaside as a chemotaxonomic marker in red algae has to be taken with great care.

Nevertheless, LMWC patterns are useful in defining each of the three classes containing unicellular red algae. Digeneaside and the sugar alcohol sorbitol (Rhodosorus) or sorbitol and dulcitol (Rhodospora) are in the two unicells of the Stylonematophyceae whereas the polyol mannitol is present in all examined members of the Rhodellophyceae (Karsten et al. 1999, 2003). Scott et al. (2006) demonstrated for the first time the occurrence of both floridoside and digeneaside in E. coxiae. Unfortunately, the presence of digeneaside in Erythrolobus was overlooked in Scott et al. (2008), who stated that all members of the Porphyridiophyceae (Erythrolobus, Porphyridium, and Flintiella) contain only floridoside. In a recent paper by Yang et al. (2010), however, T. oligopyrenoides and $E$. madagascarensis were reported to contain high amounts of floridoside and low to intermediate levels of digeneaside. This LMWC pattern is confirmed by this new species, indicating that the ultrastructural and molecular characters are well supported by this chemical information.

\section{ACKNOWLEDGEMENTS}

Mark Garland provided the Latin translation. Joe Zuccarello critically reviewed and improved the final manuscript. Field collections and laboratory culture investigations have been partially supported by grants to JAW from the Australian Research Council, Australian Biological Resources Study and Hermon Slade Foundation. This project also was partially supported by the National Research Foundation of Korea (Graduate Students Global Internship Program and KRF-2008-357-C00148) to ECY, by the National Science Foundation Assembling the Tree of Life program to HSY (DEB-0937975), by the Deutsche Forschungsgemeinschaft (DFG) to UK and by the Japan Society for the Promotion of Science (Grants-in-Aid for Scientific Research 20570081) to AY.

\section{REFERENCES}

Barrow, K. D., Karsten, U., King, R. J. \&West, J. A. 1995. Floridoside in the genus Laurencia (Rhodomelaceae: Ceramiales): a chemosystematic study. Phycologia 34:279283.

Broadwater, S. T. \& Scott, J. L. 1994. Ultrastructure of unicellular red algae. In Seckbach, J. (Ed.) Evolutionary Pathways and Enigmatic Algae: Cyanidium caldarium (Rhodophyta) and Related Cells. Kluwer, Dordrecht, pp. 215-230.

Coleman, A. W. 1985. Diversity of plastid DNA configuration among classes of eurkaryotic algae. J. Phycol. 21:1-16.

Eggert, A. \& Karsten, U. 2010. Low molecular weight carbohydrates in red algae: an ecophysiological and biochemical perspective. In Seckbach, J. \& Chapman, D. J. (Eds.) Red Algae in the Genomic Age: Cellular Origin, Life in Extreme Habitats and Astrobiology. Springer, Heidelberg, pp. 443-456.

Gantt, E. \& Conti, S. F. 1965. The ultrastructure of Porphyridium cruentum. J. Cell Biol. 26:365-381.

Gantt, E., Edwards, M. R. \& Conti, S. F. 1968. Ultrastructure of Porphyridium aerugineum: a blue-green colored Rhodophytan. J. Phycol. 4:65-71.

Guiry, M. D. \& Guiry, G. M. 2011. AlgaeBase. World-wide electronic publication, National University of Ireland, Galway. Available from: http://www.algaebase.org. Accessed Mar 3, 2011.

Hirakawa, Y., Gile, G. H., Ota, S., Keeling, P. J. \& Ishida, K. 2010. Characterization of periplastidal compartment: targeting signals in Chlorarachniophytes. Mol. Biol. Evol. 27:1538-1545.

Karsten, U., Görs, S., Eggert, A. \& West, J. A. 2007. Trehalose, digeneaside, and floridoside in the Florideophyceae (Rhodophyta): a reevaluation of its chemotaxonomic value. Phycologia 46:143-150.

Karsten, U., Michalik, D., Michalik, M. \& West, J. A. 2005. A new unusual low molecular weight carbohydrate in the red algal genus Hypoglossum (Delesseriaceae, Ceramiales) and its possible function as an osmolyte. Planta 222:319-326.

Karsten, U., West, J. A., Zuccarello, G. C., Engbrodt, R., Yokoyama, A., Hara, Y. \& Brodie, J. 2003. Low molecular weight carbohydrates of the Bangiophycidae (Rhodophyta). J. Phycol. 39:584-589.

Karsten, U., West, J. A., Zuccarello, G. C., Nixdorf, O., Barrow, K. D. \& King, R. J. 1999. Low molecular weight carbohydrate patterns in the Bangiophyceae (Rhodophyta). J. Phycol. 35:967-976.

Keane, T. M., Creevey, C. J., Pentony, M. M., Naughton, T. J. \& 
McInerney, J. O. 2006. Assessment of methods for amino acid matrix selection and their use on empirical data shows that ad hoc assumptions for choice of matrix are not justified. BMC Evol. Biol. 6:29.

Kremer, B. P. 1978. Patterns of photoassimilatory products in Pacific Rhodophyceae. Can. J. Bot. 56:1655-1659.

Le, S. Q. \& Gascuel, O. 2008. An improved general amino acid replacement matrix. Mol. Biol. Evol. 25:1307-1320.

Okaichi, T., Nishino, S. \& Imatomi, Y. 1982. Collection and mass culture. In Japanese Fisheries Society (Ed.) Toxic Phytoplankton: Occurrence, Mode of Action, and Toxins. Kôseisha-Kôseikaku, Tokyo, pp. 23-34 (in Japanese without English title).

Pickett-Heaps, J. D., West, J. A., Wilson, S. M. \& McBride, D. L. 2001. Time-lapse videomicroscopy of cell (spore) movement in red algae. Eur. J. Phycol. 36:9-22.

Pueschel, C. 1990. Cell structure. In Cole, K. M. \& Sheath, R. G. (Eds.) Biology of the Red Algae. Cambridge University Press, New York, pp. 7-41.

Ronquist, F. \& Huelsenbeck, J. P. 2003. MrBayes 3: Bayesian phylogenetic inference under mixed models. Bioinformatics 19:1572-1574.

Saunders, G. W. \& Hommersand, M. H. 2004. Assessing red algal supraordinal diversity and taxonomy in the context of contemporary systematic data. Am. J. Bot. 91:1494-1507.

Schornstein, K. L. \& Scott, J. 1982. Ultrastructure of cell division in the unicellular red alga Porphyridium purpureum. Can. J. Bot. 60:85-97.

Scott, J., Yokoyama, A., Billard, C., Fresnel, J., Hara, Y., West, K. A. \& West, J. A. 2008. Neorhodella cyanea, a new genus in the Rhodellophyceae (Rhodophyta). Phycologia 47:560-572.

Scott, J. L., Baca, B., Ott, F. D. \& West, J. A. 2006. Light and electron microscopic observations on Erythrolobus coxiae gen. et sp. nov. (Porphyridiophyceae, Rhodophyta) from Texas U.S.A. Algae 21:407-416.

Stamatakis, A. 2006. RAxML-VI-HPC: maximum likelihoodbased phylogenetic analyses with thousands of taxa and mixed models. Bioinformatics 22:2688-2690.

Swofford, D. L. 2002. PAUP*: phylogenetic analysis using parsimony ( ${ }^{*}$ and other methods). Version 4.0b10. Sinauer Associates, Sunderland, MA.

West, J. A. 2005. Long term macroalgal culture maintenance. In Anderson, R. A. (Ed.) Algal Culturing Techniques. Academic Press, New York, pp. 157-163.

West, J. A. \& Zuccarello, G. C. 1999. Biogeography of sexual and asexual populations in Bostrychia moritziana (Rhodomelaceae, Rhodophyta). Phycol. Res. 47:115-123.

Yang, E. C., Scott, J., West, J. A., Orlova, E., Gauthier, D., Küpper, F. C., Yoon, H. S. \& Karsten, U. 2010. New taxa of the Porphyridiophyceae (Rhodophyta): Timspurckia oligopyrenoides gen. et sp. nov. and Erythrolobus madagascarensis sp. nov. Phycologia 49:604-616.

Yokoyama, A., Scott, J. L., Zuccarello, G. C., Kajikawa, M., Hara, Y. \& West, J. A. 2009. Corynoplastis japonica gen. et sp. nov. and Dixoniellales ord. nov. (Rhodellophyceae, Rhodophyta) based on morphological and molecular evidence. Phycol. Res. 57:278-289.

Yoon, H. S., Müller, K. M., Sheath, R. G., Ott, F. D. \& Bhattacharya, D. 2006. Defining the major lineages of red algae (Rhodophyta). J. Phycol. 42:482-492.

Yoon, H. S., Zuccarello, G. C. \& Bhattacharya, D. 2010. Evolutionary history and taxonomy of red algae. In Seckbach, J. \& Chapman, D. J. (Eds.) Red Algae in the Genomic Age: Cellular Origin, Life in Extreme Habitats and Astrobiology. Springer, Heidelberg, pp. 25-42.

Appendix A. Key to Porphyridiophyceae species using ultrastructural features

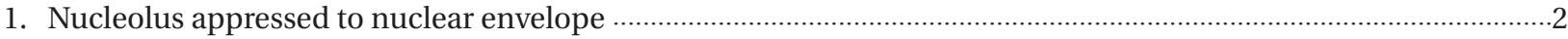

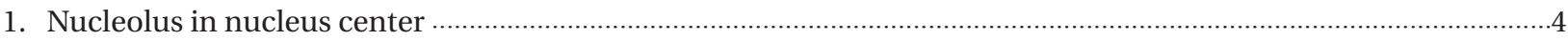

2. Multiple pyrenoids bordering cytoplasm

Timspurckia oligopyrenoides

2. Single pyrenoid embedded in plastid

3. Phycobilisomes hemispherically shaped ……...............................................................Porphyridium purpureum

3. Phycobilisomes hemisdiscoidally shaped …...............................................................Porphyridium aeruginium

4. Pyrenoids absent …................................................................................................................Flintiella sanguinaria

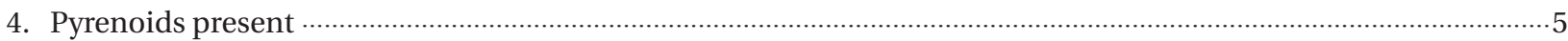

5. Predominantly multiple pyrenoids bordering cytoplasm ……..............................................Erythrolobus australicus

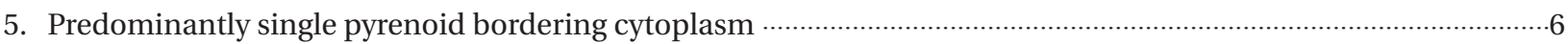

6. Cytoplasm with abundant, persistent fibrous vesicles …...............................................Erythrolobus madagascarensis

6. Cytoplasm without abundant, persistent fibrous vesicles …….................................................Erythrolobus coxiae 